\title{
Aspectos nefastos da pandemia da Covid-19 sobre a política de educação no Brasil
}

\author{
Nefarious aspects of the Covid-19 pandemic on education policy in Brazil \\ Aspectos dañinos de la pandemia del Covid-19 en la política de educación en Brasil
}

Recebido: 25/02/2021 | Revisado: 03/03/2021 | Aceito: 08/03/2021 | Publicado: 16/03/2021

\author{
Renata Maria Paiva da Costa \\ ORCID: https://orcid.org/0000-0003-2195-0104 \\ Universidade Federal do Ceará, Brasil \\ E-mail: renatampc5@gmail.com \\ Antônio Valricelio Linhares da Silva \\ ORCID: https://orcid.org/0000-0003-0941-5176 \\ Universidade Federal do Ceará, Brasil \\ E-mail: valricelio.linhares@ifce.edu.br \\ Enéas de Araújo Arrais Neto \\ ORCID: https://orcid.org/0000-0002-5919-4554 \\ Universidade Federal do Ceará, Brasil \\ E-mail: eneas.neto@ifce.edu.br
}

\begin{abstract}
Resumo
O artigo aborda a questão da educação brasileira e os efeitos provocados pela pandemia da Covid-19, principalmente no que remete à aceleração do processo de precarização dessa política social via estabelecimento do ensino remoto. Aborda brevemente os elementos que compõem o desmonte da educação no Brasil, assim como o seu sucateamento, a privatização e o ensino a distância. Para tanto, realizou-se uma pesquisa bibliográfica, por meio de livros, artigos e documentos, com o objetivo de fundamentar a discussão. Mostrou que a crise sanitária de ordem mundial trouxe o aprofundamento da desigualdade social e, em relação à educação, evidenciou a exclusão educacional de pessoas pertencentes à classe trabalhadora. Além disso, a análise indica que o contexto social então instalado fortaleceu o projeto capitalista hegemônico.
\end{abstract}

Palavras-chave: Educação brasileira; Pandemia; Precarização.

\begin{abstract}
This article addresses the issue of Brazilian education and the effects caused by the Covid-19 pandemic, mainly regarding the acceleration of the precarious process of social policies through the establishment of remote education. A brief discussion is made about elements that make up the dismantling of education in Brazil, such as recklessness, privatization, and distance learning. In order to accomplish this, a bibliographic research was carried out through books, articles and documents on the subject with the objective of supporting the discussion. The investigation shows that the world health crisis brought about a deepening of social inequality and, in relation to education, showed the educational exclusion of people belonging to the working class. In addition, the analysis indicates that the social context then installed strengthens the hegemonic capitalist project.
\end{abstract}

Keywords: Brazilian education; Pandemic; Precariousness.

\section{Resumen}

El artículo aborda el tema de la educación brasileña y los efectos causados por la pandemia de Covid-19, principalmente en lo que se refiere a la aceleración del proceso de precarización de esta política social a través del establecimiento de la educación a distancia. Se hace una breve discusión sobre los elementos que componen el desmantelamiento de la educación en Brasil, como el deterioro, la privatización y la educación a distancia. Para ello, realizamos una búsqueda bibliográfica, utilizando libros, artículos y documentos sobre el tema, con el fin de apoyar la discusión. La investigación muestra que la crisis de salud mundial provocó una profundización de la desigualdad social y, en relación a la educación, mostró la exclusión educativa de personas pertenecientes a la clase trabajadora. Además, el análisis indica que el contexto social existente fortalece el proyecto capitalista hegemónico.

Palabras clave: Educación brasileña; Pandemia; Precarización.

\section{Introdução}

O mundo contemporâneo está sendo ferozmente atingido pela pandemia da Covid-19, acarretando sérias consequências não apenas para a saúde das pessoas, mas também para as diversas dimensões da vida humana e para a 
economia e política dos países em âmbito mundial. Assim, o presente artigo tem por objetivo desenvolver uma análise acerca da educação brasileira no contexto da crise sanitária de 2020, sobre qual perspectiva essa política está sendo alicerçada e sobre os possíveis efeitos da escolha pelo formato de ensino remoto.

Dessa maneira, a análise é fundamentada em um estudo bibliográfico, em que abordamos livros, artigos e documentos oficiais, bem como se trata de uma discussão ancorada da teoria crítico-dialética. Destarte, na primeira parte fazemos uma contextualização da pandemia, desde a manifestação da doença até sua disseminação no planeta, o que acarretou milhares de mortes humanas e uma série de outros prejuízos para a sociedade, traduzindo-se em uma verdadeira tragédia humanitária. No segundo ponto do estudo realizamos uma discussão sobre a educação brasileira moldada sob as normas do sistema capitalista de produção e o severo processo de precarização no cenário da pandemia. Por fim, indicamos alguns elementos identificados ao longo do texto, os quais explicitam que a crise gerada pelo novo coronavírus trouxe impactos negativos para as políticas sociais no Brasil, dentre elas, as voltadas à educação, agudizando o processo de precarização já vivenciado há anos, provocado pela subordinação aos propósitos do capital financeiro.

\section{Metodologia}

O objeto de investigação abordado em nossa análise é a educação e as políticas educacionais, com a especificidade de se tratar de uma condição de excepcionalidade na forma e nos meios de manutenção das atividades de ensino diante dos impactos da pandemia causada pelo novo coronavírus. Para realizar uma análise do objeto em questão, fizemos uso da pesquisa qualitativa, fundamentando a discussão na teoria crítica de Marx e dialogando com elaborações teóricas do campo da educação, com a finalidade de apreendermos o seu movimento, partindo do real para atingir a sua essência, e compreendendo-o como uma síntese de múltiplas determinações (Marx, 2011).

O método de investigação em sentido amplo, como concepção de mundo e de vínculo entre uma realidade específica e a totalidade social que lhe é determinante, permite-nos explorar o fenômeno e seus nexos com a realidade social. Portanto, para este estudo, adotamos o método dialético na sua dimensão científica e filosófica de compreensão do caráter histórico e do sentido lógico, isto é, das determinações internas dos fenômenos sociais, numa palavra, um método mais sensível às contradições e às múltiplas determinações do real (Demo, 2000), "que permite uma apreensão radical da realidade" (Frigotto, 1999, p. 73).

Com o intuito de compreender o objeto de estudo em todas as suas nuanças, lançamos mão da pesquisa de natureza qualitativa, a qual nos possibilita perceber o objeto para além do seu caráter quantificável, decompondo-o e recompondo-o por meio de uma análise aprofundada do "mundo dos significados das ações e relações humanas, um lado não perceptível e não captável em equações, médias e estatísticas" (Minayo, 1994, p. 22). Ademais, alicerçamos o estudo numa criteriosa pesquisa bibliográfica que, segundo Gil (2002, p. 45), possibilita "ao investigador a cobertura de uma gama de fenômenos muito mais ampla do que aquela que poderia pesquisar diretamente". Desse modo, auxiliando o pesquisador a se apropriar do objeto por meio das fontes de conhecimento já elaborados acerca do problema abordado.

Assim, adotamos elementos da análise documental como técnica valiosa na abordagem de dados qualitativos, de fontes de informações factuais que evidenciam hipóteses formuladas a partir de uma espécie de desconfiança empírica. Como a pesquisa documental indica problemas que só podem ser compreendidos adequadamente por meio de outros métodos (Lüdke \& André, 2012), procuramos fundamentação na literatura que aborda aspectos políticos, econômicos e sociais como determinantes dos problemas evidenciados pelos dados documentais. Esses problemas, intrínsecos ao nosso objeto de estudo, impactam sobre as pessoas, sendo o caso dos trabalhadores da educação, como, por exemplo, a insegurança e a ansiedade em 
face do risco de contrair a Covid-19 e de ter que lidar com novas ferramentas laborais, trabalho remoto, ensino remoto; numa só palavra, a nova precarização do trabalho (Antunes, 2020b).

\section{Há um Vírus no Meio do Caminho: Contextualizando a Pandemia no Território Brasileiro}

Em 2020 a sociedade testemunha uma grave crise sanitária causada pelo surgimento e disseminação do novo coronavírus (Sars-Cov-2). A pandemia da Covid-19 - doença causada pelo referido vírus, marca a história da humanidade como um dos eventos mais nefastos já vivenciados, em que milhares de vidas humanas foram perdidas e, outras tantas, dilapidadas em todo o planeta. O vírus mortal começa a circular no mundo no final do ano de 2019, inicialmente na cidade de Wuhan, na China. Devido à sua alta capacidade de proliferação e contágio, atingiu os continentes de forma célere, ao ponto de, no dia 11 de março de 2020, a Organização Mundial da Saúde (OMS), por meio do pronunciamento de seu diretor geral, Tedros Adhanom, elevar o estado de contaminação pela Covid-19 à pandemia.

A crise sanitária mundial foi instalada e, nos países periféricos, como o Brasil, somou-se a uma crise econômica instaurada há anos, agudizando ainda mais a problemática. Dessa forma, chefes de Estado do mundo todo começaram a instituir planos para a prevenção e enfrentamento à pandemia, tomando medidas que restringiam a circulação de pessoas e de produtos, bem como adotando protocolos de atendimento para o tratamento da doença nas unidades de saúde. Evidenciamos que, no caso da Covid-19, ainda não há uma terapêutica definida para o tratamento da doença, portanto, são criados protocolos experimentais no âmbito hospitalar à medida que a utilização de medicamentos e de outros procedimentos médicos vão surtindo efeitos positivos. Por outro lado, os esforços de cientistas de vários países, debruçados sobre estudos e pesquisas acerca da estrutura do vírus, culminaram no desenvolvimento de vacinas contra a doença, possibilitando o início do processo de imunização da população em âmbito mundial. Embora a ciência tenha realizado esse feito em tempo recorde, sabemos que a imunização caminha a passos lentos, principalmente se levarmos em consideração que a demanda pela vacina, neste momento, é superior à capacidade de produção. Nesse sentido, todos os esforços voltados para minimizar a proliferação da enfermidade, por meio da adoção de medidas inerentes ao distanciamento/isolamento social, são essenciais.

Nesse contexto, os países de todos os continentes começaram a recomendar o distanciamento social e, até mesmo, decretar quarentena para os casos confirmados, como meio de prevenção à contaminação de pessoas, já que o vírus detém alto nível de transmissibilidade. Observamos, então, o fechamento de portos, aeroportos e fronteiras, a instalação de barreiras sanitárias em cidades, a interrupção das atividades consideradas não essenciais, a suspensão de calendários letivos - com o fechamento de creches, escolas e universidades, a cessação das atividades laborativas presenciais e a instauração do home office e do teletrabalho, para além do incentivo à ampliação de atitudes de higiene individual e coletiva. Tudo isso com o objetivo de desacelerar o crescimento do número de casos da doença e de não comprometer o sistema de saúde das localidades atingidas.

Tais providências, entretanto, não foram suficientes para impedir a rápida contaminação de pessoas e a mortalidade em decorrência da Covid-19 em muitos países. Assim, o número de indivíduos acometidos pela moléstia e de mortos vem crescendo exponencialmente, dando indícios de que a pandemia ainda está longe de ser controlada. De acordo com a Organização Pan-americana de Saúde (OPAS) (https://www.paho.org/pt/covid19, recuperado em 26 de janeiro, 2021), ligada à OMS, até o dia 22 de janeiro de 2021 o mundo contabilizava 96.267.473 casos confirmados de Covid-19, com 2.082.745 mortes. Na região das Américas são 42.807 .169 casos confirmados e 983.878 vidas ceifadas, segundo o mesmo órgão. Conforme os dados do Ministério da Saúde (https://susanalitico.saude.gov.br/extensions/Covid-19_html/Covid-19_html.html, recuperado em 26 de janeiro, 2021), até o dia 25 de janeiro de 2021 o Brasil apresentava 8.871 .393 casos confirmados acumulados, com 217.664 óbitos notificados. É válido ressaltar que a realidade de subnotificações no país é considerável, tanto 
no que se refere ao número de casos confirmados quanto ao montante das mortes. Dessa forma, as estatísticas de casos e de mortes podem ser ainda muito maiores do que as que são oficialmente publicadas.

Os números revelam uma tragédia humanitária, a qual é vivenciada de diferentes modos, a depender do país ou da região onde se habita e da classe social a qual pertence o indivíduo acometido pela doença. Ao fazermos, também, um recorte de cor/etnia, de gênero e de geração, percebemos que as maneiras de resistir e enfrentar a pandemia se tornam mais frágeis. Conforme expõe Harvey (2020), a Covid-19 revela uma pandemia que possui um caráter de classe, gênero e raça, em que o conjunto dos/as trabalhadores/as, bem como os segmentos mais vulnerabilizados da sociedade - negros/as, mulheres, idosos/as e imigrantes, estão mais expostos às consequências danosas dessa catástrofe. Desse modo, o discurso de que "todos/as estão no mesmo barco" trata-se de uma falácia, pois a experiência mostra que "todos/as estão no mesmo mar": uns em botes e outros sem sequer coletes salva-vidas. A análise feita por Antunes (2020a, p. 14) corrobora com a visão de que a forma de vivenciar a pandemia depende da condição (classe social, gênero, raça/etnia) na qual se insere cada pessoa, grupo ou coletividade.

Dada a divisão sociossexual e racial do trabalho em sua nova morfologia, as mulheres trabalhadoras brancas sofrem mais que os homens brancos (basta ver que os altos índices de violência doméstica e feminicídio se ampliam durante a pandemia), enquanto que as trabalhadoras negras são ainda mais penalizadas que as brancas (veja-se o exemplo das trabalhadoras domésticas no Brasil, que totalizam 6,2 milhões, das quais 68\% são negras) [grifo do autor].

Diante da problemática sanitária, governantes de diversos países em todo o mundo mobilizaram esforços para implementar planos de prevenção e enfrentamento à doença, visando desacelerar o avanço nos territórios, bem como buscar meios para sua erradicação com base em pesquisas científicas. Nesse contexto, reconhece-se a existência de opiniões contrárias à tomada de medidas extremas de distanciamento social e de concepções que subestimam a gravidade da doença, elaboradas por parte de uma população ligada a vertentes religiosas mais conservadoras, assim como por parte de alguns líderes de nações.

A séria questão do "negacionismo científico", tão presente na realidade brasileira, especialmente no gabinete da Presidência da República, assevera a crise - ou as crises (pandêmica, econômica, política) - então vivenciada, trazendo consigo um modo de gestão relapso, ineficiente e perverso. Emerge, então, no país uma forma de gerir a pandemia fundamentada numa atitude de minimização da gravidade da doença, na manipulação dos números de infectados e de óbitos pela Covid-19 e na prescrição de tratamentos milagrosos, estes com uso de drogas cuja eficácia contra a doença não possui comprovação científica. É nítida a intencional apatia do governo, o qual não esboça nenhum plano de ação para mitigar os impactos desse problema de saúde pública, eximindo-se de suas responsabilidades, conforme prega a cartilha neoliberal.

De acordo com o Portal G1 (https://g1.globo.com/, recuperado em 01 de fevereiro de 2021), o estudo realizado pelo thinktank (grupo de pesquisas), do Lowy Institute, de Sydney, Austrália, e publicado em janeiro de 2021, afirma-se que o Brasil é o pior país do mundo na gestão da pandemia de Covid-19. O levantamento, feito em quase 100 países, indica que, de modo geral, a resposta para o enfrentamento da pandemia foi medíocre, contudo, algumas nações administraram melhor as ações de contenção do que outras, mas a maioria apresentou um desempenho insatisfatório nessa questão. Conforme publica o site da BBC News (https://www.bbc.com/, recuperado em 01 de fevereiro, 2021), a referida pesquisa levou em consideração dados como o total de casos e de mortes por Covid-19 em cada país, a oferta de testes e o percentual da população afetada pela pandemia. Desse modo, com base nesses indicadores, os países receberam notas numa escala de zero (pior desempenho) a cem (melhor desempenho). O Brasil recebeu nota 4,3, ficando na posição de pior desempenho.

O problema do negacionismo não diz respeito apenas à ignorância ou desconhecimento da doença e de seus efeitos nocivos à sociedade como um todo, ele também evidencia o perfil de um Estado neoliberal que tende a reduzir sua intervenção perante a problemática social instalada, operando, no campo ideológico, uma permanente e ampliada inversão da realidade. Tal posicionamento mostra um Estado que não planeja uma tomada de atitude de contenção e combate à pandemia, que não se preocupa com as condições sociais dos indivíduos e que prioriza o caráter economicista da crise sanitária. Assim, observamos, 
cotidianamente, os apelos ao retorno imediato das atividades não essenciais, à reabertura do comércio e da indústria, à retomada das atividades de lazer, de entretenimento e escolares, tudo isso justificado pelo refrão: “a economia não pode parar!", principalmente, numa conjuntura em que o consumo de bens e serviços se expande cada vez mais, mostrando-se como um processo que alavanca e dá suporte ao capitalismo.

Notamos que, no modo de produção capitalista consolidado, mesmo diante de um contexto de pandemia, em que centenas de milhares de vidas se esvaem, nada se sobrepõe à produção e ao lucro. Dessa forma, no sistema de metabolismo antissocial do capital, como se refere Antunes (2020a), tudo é permitido e incentivado quando o objetivo é a constante valorização do valor. Isto é, antes de se salvarem vidas, é preciso salvar o sistema.

Nesse contexto, o chamamento à retomada das atividades laborais ecoa repetidamente no discurso dos detentores dos poderes político e econômico, apesar das recomendações dos organismos internacionais de saúde para manter o isolamento social e evitar o retorno precoce à rotina de trabalho, sob pena de se estabelecer um novo cenário de contaminação ascendente. Assim, nesse terreno contraditório, podemos observar algumas situações de acirramento da precarização das relações de trabalho que a pandemia em si não provocou, mas potencializou um fenômeno que já estava instalado na realidade.

É evidente que a classe trabalhadora, a qual dispõe apenas da sua força de trabalho para garantir a sobrevivência, é o segmento que mais sofre os impactos da pandemia. Para além da realidade de espoliação dos seus direitos dia a dia, os trabalhadores e as trabalhadoras vivenciam, no contexto pandêmico, a exacerbação da exploração e a fragilização das relações de trabalho. Desse modo, observamos diariamente o crescimento das taxas de desemprego e de subemprego no Brasil e no mundo, em que milhares de pessoas que vendem sua força de trabalho têm seus direitos trabalhistas tolhidos, bem como se submetem a condições degradantes para obter o mínimo necessário à sua sobrevivência e de sua prole.

No caso do Brasil, por exemplo, dados do Instituto Brasileiro de Geografia e Estatística (IBGE) (https://www.ibge.gov.br/explica/desemprego.php, recuperado em 11 de setembro, 2020) mostram que, no segundo semestre de 2020, a taxa de desemprego é de 11,8\%, atingindo 12,8 milhões de brasileiros. O Gráfico 1, abaixo, explicita o número de pessoas desocupadas no segundo trimestre desse ano, indicando a tendência de elevação do desemprego e da consequente desigualdade social que torna o abismo entre ricos e pobres cada vez mais profundo no País.

Gráfico 1: Pessoas de 14 anos ou mais de idade, desocupadas na semana de referência (Mil pessoas) - Brasil - $2^{\circ}$ trimestre 2020

Pessoas de 14 anos ou mais de idade, desocupadas na semana de referência (Mil pessoas) - Brasil $-2^{\circ}$ trimestre 2020

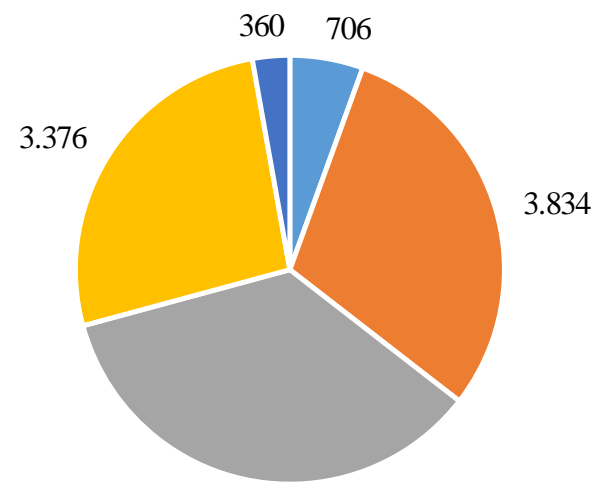

4.514

" 14 a 17 anos $" 18$ a 24 anos -25 a 39 anos $" 40$ a 59 anos $\quad 60$ anos ou mais

Fonte: IBGE- Pesquisa Nacional por Amostra de Domicílios Contínua trimestral. 
Enquanto finalizávamos este estudo, uma nova Pesquisa Nacional por Amostra de Domicílios (PNAD/Covid-19, de dezembro de 2020) já apontava um total de 14 milhões de desempregados no acumulado de novembro, saltando daqueles 11,8\%, para 14,2\% na taxa de desocupação (https://www.brasildefato.com.br/2020/12/23/ibge-desemprego-bate-novo-recordee-aumenta-quase-40-em-seis-meses, recuperado em 4 de fevereiro, 2021).

Do mesmo modo, podemos considerar, ainda, a existência de outro contingente de pessoas que estão inseridas no mercado de trabalho de forma precária, sem vínculos formais, com baixos salários, jornadas elevadas e em condições indignas de trabalho, tal como os/as trabalhadores/as "uberizados/as".

A pandemia também impactou os trabalhadores de plataformas digitais e aplicativos, uma massa que não parava de se expandir e que experimentava as condições da chamada uberização do trabalho. Sem outra possibilidade de encontrar trabalho imediato, trabalhadores e trabalhadoras buscavam "emprego" no Uber, UberEats, 99, Cabify, Rappi, Ifood, Amazon, etc. Tentavam fugir do flagelo maior, o do desemprego. Saíam do desemprego para a uberização, essa nova modalidade de servidão (Antunes, 2020a, p. 15) [grifo do autor].

Ora, é nítido que, em um cenário de pandemia, o conjunto de trabalhadores é ferozmente atingido, entretanto, aqueles que se encontram nessas duas condições acima identificadas - de desemprego ou de trabalho precário, sofrem mais fortemente os efeitos da crise. A grande massa de desempregados não tem recurso sequer para acessar o mínimo necessário à subsistência, como alimentos, remédios, produtos de higiene, habitação, dentre outros, ficando à mercê da própria sorte ou de políticas sociais paliativas emergenciais, a exemplo dos programas de transferência de renda do governo federal.

Já os/as trabalhadores precarizados/as, "uberizados/as" e espoliados/as são expostos a condições insalubres que os/as tornam vulneráveis à contaminação nas ruas, nos transportes coletivos, no contato físico, nas inúmeras trocas diárias decorrentes de sua ocupação.

Outro contingente de trabalhadores/as, talvez em situação menos insalubre, manteve-se confinado em seus domicílios aderindo à modalidade de trabalho remoto, o qual, se não expõe as pessoas ao perigo da rua, deixam-nas expostas a jornadas de trabalho prolongadas e agudizadas pela sobreposição ao trabalho doméstico, à pressão psicológica por produtividade, ao controle exacerbado e a situações de assédio moral. São condições a que trabalhadores/as estão submetidos/as e que podem gerar estados de adoecimento psíquico-emocional e até suicídio, fenômeno que ocorre especialmente entre trabalhadores/as submetidos/as a precários contratos de trabalho, com formas variadas, como os chamados "zerados", "uberizados", "pejotizados", "intermitentes", "flexíveis" (Antunes, 2020b, p. 37).

É evidente, entretanto, que tais características são inerentes à relação capital-trabalho em qualquer tempo. A diferença, nesse momento, é que essa dinâmica fabril, própria dos estabelecimentos empregadores, apenas foi transplantada para as residências dos/as trabalhadores/as, fazendo destes/as fiscais ou bedéis de si próprios, ou ainda, mais que isso, como observa Antunes (ibidem, p. 39): “... o resultado mais grave dessa processualidade é o advento de uma nova era de escravidão digital, que se combina com a expansão explosiva dos intermitentes globais" [grifo do autor].

Percebemos, mais uma vez, que a face perversa do capitalismo se manifesta veementemente, apesar do cenário de pandemia. Ao mesmo tempo que intensifica a exploração da classe trabalhadora, expropriando-a de seus direitos, fortalece um Estado, cujo modo de gestão política e econômica enaltece as relações mercantis em detrimento do estabelecimento de um sistema de proteção social ampliado. Assim, parece ser mera ilusão a ideia de que a pandemia do novo coronavírus provocará uma reconfiguração na maneira de operar do Estado, aproximando-se de um caráter intervencionista. Pelo contrário, a experiência brasileira mostra que a retração ou, até mesmo, a ausência do Estado é uma sólida realidade. 


\section{Reflexões Sobre a Educação no Brasil em Tempos de Pandemia}

Traçar uma reflexão acerca da política de educação brasileira na conjuntura de pandemia requer, antes de tudo, a compreensão de que essa política vem sofrendo um processo de desmantelamento há alguns anos e que a crise sanitária instalada em 2020 trouxe agravos a tal processo. Assim, o desmonte das políticas públicas como um todo no Brasil, em especial a de educação, faz parte do projeto de consolidação do neoliberalismo no país, por meio de um movimento que combina redução de investimentos, sucateamento dos serviços prestados e privatização. A Emenda Constitucional n. ${ }^{\circ} 95 / 2016^{1}$ representa a materialização desse projeto, tornando-se emblemática no tocante à retração do Estado perante o financiamento das políticas públicas em todo o território. Nesta discussão, abordaremos, pelo menos, três elementos que confirmam a tendência de corrosão da educação pública no Brasil, agravada pela pandemia da Covid-19: precarização e privatização, fragilização da relação ensino/aprendizagem e solidificação da educação à distância (EAD).

Ora, não é recente o fato de que os governos vêm, ao longo de anos, reduzindo o orçamento destinado à educação, muito embora tenhamos vivido um período de ampliação do investimento na educação pública, principalmente a de nível superior no âmbito federal, em meados dos anos 2000. O tempo presente mostra que, a cada exercício financeiro, o corte de recursos para a educação aumenta, provocando a diminuição da qualidade do serviço prestado. Ainda que o planejamento orçamentário expresse um investimento vultoso, este ainda se apresenta muito aquém das reais necessidades e, além disso, ao longo de cada ano, incidem contingenciamentos sobre ele, resultando que nem tudo aquilo que foi planejado é, realmente, o executado. Seguindo mais do que recomenda a Emenda Constitucional referida, a quatro meses de fechar o ano de 2020 , o Ministério da Educação (MEC) havia aplicado menos que metade do seu orçamento, $48 \%$. (https://ultimosegundo.ig.com.br/educacao/2020-09-03/em-meio-a-pandemia-mec-nao-usou-metade-da-verba-disponivel-paraa-pasta-em-2020.html, recuperado em 4 de fevereiro, 2021).

Destarte, o cenário atual da educação brasileira revela um caráter de sucateamento geral, o qual atinge não somente o âmbito da infraestrutura das unidades de ensino, mas também degrada a força de trabalho que lá reside, com baixos salários, sobrecarga de tarefas, déficit de profissionais, incidência de assédios, ausência de uma política de recursos humanos, etc. Isso sem contar com a insuficiência de recursos para programas de atendimento a educandos em situação de vulnerabilidade socioeconômica, bem como com o corte de bolsas de fomento à pesquisa. É coerente dizer, entretanto, que a pandemia da Covid-19 não inaugura os problemas inerentes à educação no país, porém, evidencia o processo intencional de precarização. Intencional porque revela, por um lado, a realidade de deterioração dessa política pública e o encolhimento da responsabilidade do Estado, por outro, abre espaço para o projeto de expansão da privatização do ensino, sob a justificativa de esta se mostrar como a fórmula mais eficaz para salvar a educação no Brasil².

Tais problemáticas foram asseveradas devido à pandemia, a qual não apenas forçou a interrupção das atividades acadêmicas presenciais, como também trouxe consigo um modelo de ensino improvisado, mediado pelas tecnologias de

\footnotetext{
${ }^{1}$ A Emenda Constitucional n. ${ }^{\circ}$ 95, de 15 de dezembro de 2016, institui o Novo Regime Fiscal no âmbito dos Orçamentos Fiscal e da Seguridade Social da União, que vigorará por 20 (vinte) exercícios financeiros, impondo limites para as despesas primárias, encaixando-se nelas saúde, educação, previdência, dentre outras. (http://www.planalto.gov.br/ccivil_03/constituicao/Emendas/Emc/emc95.htm, recuperado em 28 de setembro, 2020).

${ }^{2} \mathrm{Na}$ contemporaneidade, a educação se apresenta como um nicho lucrativo e adentra à lógica mercantil capitalista. Adrião (2017) elabora uma análise acerca da privatização da educação básica no Brasil, considerando que a mesma se manifesta e se subordina à financeirização econômica, como parte de um processo global de violação dos direitos sociais. Tal movimento objetiva transferir a gestão da educação pública para o setor privado, por meio de parcerias público-privadas, do estabelecimento de contratos de gestão e pela adoção, por redes públicas, dos sistemas privados de ensino, os quais também incidem sobre os currículos escolares. Com isso, pretende-se tornar a educação um serviço público não estatal, por meio, principalmente, do estabelecimento de parcerias com Organizações da Sociedade Civil de Interesse Público (OSCIP) como via para formalizar a transferência da responsabilidade da gestão da educação para o setor privado.
} 
informação e comunicação (TIC). Eis, então, o segundo elemento de análise acima indicado, qual seja, a fragilização da relação ensino/aprendizagem.

O estabelecimento do ensino remoto como prática alternativa vislumbrada para minimizar os prejuízos com a interrupção do calendário letivo tem provocado inúmeras discussões acerca de sua viabilidade no contexto brasileiro. Em primeiro lugar, considerando-se o país com dimensões continentais, são evidentes as desigualdades regionais, em que observamos a existência de grandes metrópoles contrastando com localidades menos desenvolvidas, cujos sistemas de telecomunicações são deficientes, dificultando o acesso das pessoas à informação e à comunicação, de um modo geral, e, especialmente, o segmento estudantil às aulas remotas.

Em segundo plano, observamos a questão da desigualdade social, em que uma grande massa populacional pertencente à classe social economicamente desfavorecida não possui recursos materiais suficientes para obter os meios necessários ao acompanhamento do ensino remoto, como: celular, notebook, tablet, planos de acesso à Internet, pacote de dados móveis, dentre outros. Desse modo, não podemos omitir o fato de que as formas de sentir, vivenciar e resistir à pandemia são diferentes, a depender da classe ou grupo social a/ao qual o indivíduo pertence. A crise sanitária expôs, de forma patente, o antagonismo existente entre as classes e revelou, de forma nítida, quem seria incluído ou excluído do processo educacional.

Os impactos intertemporais da pandemia da Covid-19 sobre a educação são preocupantes pois reproduzem de modo ampliado assimetrias previamente existentes nas sociedades, de modo que os atores econômicos privilegiados e com amplo acesso ao ensino privado e às Tecnologias de Informação e Comunicação (TICs) conseguem minimizar os efeitos pandêmicos no curto prazo por meio da continuidade educacional via EAD em contraposição a atores econômicos mais vulneráveis (Senhoras, 2020, p. 134).

Como consequência, um número considerável de estudantes é alijado do processo ensino/aprendizagem, simplesmente pelo fato de não ter como acompanhar as aulas remotamente. O Quadro 1, abaixo, mostra a pesquisa realizada pelo IBGE no ano de 2018, Pesquisa Nacional por Amostra de Domicílios - PNAD Contínua TIC (https://www.ibge.gov.br/estatisticas/sociais/trabalho/, recuperado em 29 de setembro, 2020), a qual expõe a disparidade regional concernente ao acesso à Internet nos domicílios brasileiros: 
Quadro 1: Domicílios particulares permanentes, por situação do domicílio e existência de utilização da Internet, segundo as Grandes Regiões $-4^{\circ}$ trimestre 2018.

\begin{tabular}{|c|c|c|c|c|c|c|}
\hline \multirow{4}{*}{$\begin{array}{l}\text { Grandes } \\
\text { Regiões }\end{array}$} & \multicolumn{6}{|c|}{ Domicílios particulares permanentes } \\
\hline & \multicolumn{3}{|c|}{ Valores absolutos (1000 domicílios) } & \multicolumn{3}{|c|}{ Valores relativos (\%) } \\
\hline & \multirow[t]{2}{*}{ Total } & \multicolumn{2}{|c|}{$\begin{array}{l}\text { Existência de utilização da } \\
\text { Internet }\end{array}$} & \multirow[t]{2}{*}{ Total } & \multicolumn{2}{|c|}{$\begin{array}{l}\text { Existência de utilização } \\
\text { da Internet }\end{array}$} \\
\hline & & Havia & Não havia & & Havia & Não havia \\
\hline \multicolumn{7}{|c|}{ Urbana } \\
\hline Brasil & 62072 & 51995 & 10077 & 100,0 & 83,8 & 16,2 \\
\hline Norte & 4153 & 3448 & 705 & 100,0 & 83,0 & 17,0 \\
\hline Nordeste & 14073 & 10866 & 3207 & 100,0 & 77,2 & 22,8 \\
\hline Sudeste & 29361 & 25390 & 3971 & 100,0 & 86,5 & 13,5 \\
\hline Sul & 9452 & 7941 & 1511 & 100,0 & 84,0 & 16,0 \\
\hline $\begin{array}{l}\text { Centro- } \\
\text { Oeste }\end{array}$ & 5034 & 4351 & 682 & 100,0 & 86,4 & 13,6 \\
\hline \multicolumn{7}{|c|}{ Rural } \\
\hline Brasil & 9666 & 4752 & 4914 & 100,0 & 49,2 & $\mathbf{5 0 , 8}$ \\
\hline Norte & 1156 & 383 & 774 & 100,0 & 33,1 & 66,9 \\
\hline Nordeste & 4596 & 2032 & 2564 & 100,0 & 44,2 & 55,8 \\
\hline Sudeste & 1945 & 1156 & 789 & 100,0 & 59,4 & 40,6 \\
\hline Sul & 1420 & 871 & 549 & 100,0 & 61,4 & 38,6 \\
\hline $\begin{array}{l}\text { Centro- } \\
\text { Oeste }\end{array}$ & 548 & 309 & 239 & 100,0 & 56,5 & 43,5 \\
\hline
\end{tabular}

Fonte: IBGE, Diretoria de Pesquisas, Coordenação de Trabalho e Rendimento, Pesquisa Nacional por Amostra de Domicílios Contínua 2018.

O Quadro 1 expressa que em mais da metade dos domicílios brasileiros $(50,8 \%)$ localizados na zona rural não havia existência de utilização de Internet, situação essa agravada nas regiões mais pobres do país, Norte e Nordeste, onde 66,9\% e $55,8 \%$ dos domicílios rurais, respectivamente, não tinham acesso a esse recurso informacional. Apesar de a pesquisa mostrar que, na região urbana, $83,8 \%$ das residências utilizavam a Internet, isso não quer dizer que a conexão seja de boa qualidade, que permita o acompanhamento das atividades acadêmicas sem interrupções.

Esse traço da desigualdade de acesso às TICs no país corrobora com a impossibilidade de acesso à educação de forma igualitária para um grande número de estudantes no modelo de ensino remoto. Nesse sentido, isso representa o fortalecimento de um processo de exclusão educacional de uma parcela da sociedade que vem sendo, ao longo do tempo, alijada de seus direitos.

Concomitante ao acesso desigual às TICs, outros fatores corroboram para a fragilização do processo de ensino/aprendizagem, que dizem respeito às contradições inerentes ao contexto da sociedade de classes. Dessa forma, observamos que as condições socioeconômicas dos estudantes não somente impedem ou limitam o acesso às tecnologias imprescindíveis ao ensino remoto, mas também impõem situações que inviabilizam a aprendizagem, como: a insuficiência de recursos financeiros; a ausência de ambientes reservados nos domicílios, que propiciem uma atmosfera de concentração; a 
inexistência/deficiência de alimentação; a existência de habitações com várias famílias coabitando; conflitos familiares; a violência presente nas comunidades; dentre outras questões relacionadas ao contexto que envolve grande parte dos/das estudantes brasileiros/as.

Conforme Marinho e Freitas (2020), o debate sobre do ensino remoto ultrapassa a mera discussão acerca da inclusão digital. Para as autoras, a reflexão sobre a viabilidade de um ambiente de estudos perpassa, também, pela necessidade de estruturas domiciliares que propiciem locais adequados para o estudo reservado e para a concentração, realidade essa que abarca uma parcela ínfima de estudantes no país. Da mesma forma, Andrade, Barbosa, Cardoso e Oliveira (2021, p. 4) indicam que "as pessoas com deficiência podem enfrentar ainda outros desafios com as aulas remotas, pois dependendo da deficiência podem necessitar de uma atenção mais individualizada e sistema de apoio". Assim, esse modelo educativo tende a fragilizar, ainda mais, o processo de formação das pessoas que possuem algum tipo de comprometimento, seja de ordem econômica, seja do ponto de vista da acessibilidade.

Para além desses fatores limitantes à relação ensino/aprendizagem, as aulas remotas, mediadas por plataformas digitais, introduzem novos desafios a professores/as, aos/às quais são exigidas novas metodologias de transmissão de conteúdo para os/as discentes. Acrescentam-se, desse modo, novas demandas ao trabalho desses/as profissionais que, em muitos casos, não têm aptidão ou familiaridade com o uso das TIC. Não obstante, observamos, ainda, dentro dessa dinâmica, novas formas de controle do trabalho e a perda da autonomia dos/as docentes. Além disso, muitos desses/as trabalhadores/as têm, a partir de então, que dividir a prática da docência com a rotina doméstica, em um mesmo tempo e espaço, fazendo com que a sobrecarga de trabalho se intensifique, podendo acarretar o adoecimento físico e psíquico.

Para Gonçalves, Lima e Freitas (2020), a suspensão das aulas presenciais e a adoção das aulas remotas revelaram que, no mundo inteiro, os sistemas educativos não estavam preparados para essa nova roupagem, bem como os/as professores/as não estavam treinados para ministrar aulas on-line, e que o acesso dos/das estudantes às tecnologias era desigual, sobretudo nos países mais pobres. Os autores acrescentam que as dificuldades concernentes ao momento trouxeram um sofrimento a mais aos/às professores/as, pois a docência é considerada uma atividade genuinamente relacional e que o envolvimento afetivo de docentes com seus/suas alunos/as e sua preocupação com a aprendizagem são fontes de desgaste, mas também são fatores de gratificação e realização.

Ademais, podemos pontuar que, nessa realidade, há uma perda no processo de construção do conhecimento, tendo em vista o enxugamento dos conteúdos das disciplinas, a redução da dinâmica do debate, a diminuição da participação efetiva de estudantes e o aligeiramento das atividades letivas. Dessa maneira, a adoção de recursos tecnológicos, apenas, não significa imprimir um caráter eficiente e moderno à forma de desenvolver a educação no país, como indica Soares (2020, p. 8):

O que se pode observar é a "modernidade" tecnológica servindo para reforçar o que há de mais arcaico pedagogicamente. É a modernização conservadora da educação, o intento de inovar para manter as estruturas sociais tal qual estão. O educar vira sinônimo de conteúdo e aula expositiva, os projetos, as peças de teatro e demais processos educativos vão deixando de fazer parte das metodologias de aprendizagem, pois são impossíveis de se desenvolver nessa lógica virtual [. . .] As discussões, debates de ideias e contestações que já eram difíceis na estrutura verticalizada da escola, torna-se ainda mais complexo e até sem sentido em uma escola virtual.

Assim, o ensino remoto é uma alternativa que foi imposta diante de uma crise sanitária, mas que parece não ter sido pensada de forma ponderada. O imediatismo da resposta à problemática da educação no contexto da pandemia impediu que fossem avaliadas as limitações ao ensino e à aprendizagem. Não pretendemos dizer com isso, no entanto, que o retorno às aulas presenciais deva ser precipitado, porém, o que desejamos é evidenciar o perigo que esse modelo de ensino representa para a ampliação da desigualdade educacional no Brasil. 
O debate em torno do ensino remoto sugere uma questão ainda mais delicada para a política de educação no país, que se trata do terceiro elemento de discussão indicado no texto: a ampliação e o fortalecimento da EAD.

No cenário da pandemia a implantação das aulas remotas não se configurou como um equívoco para uma parcela da sociedade interessada em imprimir um novo caráter à educação nacional alinhada com os objetivos neoliberais. Pelo contrário, representou, principalmente, uma oportunidade de consolidar um projeto de expansão da EAD para diferentes níveis e modalidades de educação. "A oportunidade que se apresentou com o distanciamento social criou condições para que, no póspandemia, "barreiras fossem removidas", não impedindo a efetivação de uma educação mediada por tecnologia no currículo escolar" (Fiera, Evangelista \& Flores, 2020, p. 24). É como se o ensino remoto fosse um trampolim para um mergulho profundo no oceano da EAD.

Ora, não é de hoje que a EAD e seus defensores tentam vencer as resistências contra sua expansão, tanto que essa modalidade já detém um notável protagonismo nos ensinos técnico e superior (graduação e pós-graduação) na atualidade. A questão apresentada no momento é a de que a pandemia descortinou a oportunidade perfeita para a ampliação do projeto educacional a distância, abrangendo, inclusive, a educação básica. Alguns/as autores/as indicam que a EAD será uma herança deixada pela pandemia e representará a entrega da educação nacional aos interesses do capital.

Um olhar mais atento sobre essa questão nos mostra que no salto do ensino remoto em direção à EAD estão articulados pelo menos três aspectos que privilegiam o sistema capitalista e seu projeto de privatização da educação como um todo: o papel do Estado, os interesses dos grupos educacionais e os ganhos das grandes empresas de tecnologias.

A expansão da EAD, estimulada no contexto da crise de saúde no território nacional, representa a materialização da investida neoliberal contra a educação no país, em que o Estado reduz o investimento e transfere a gerência da política de educação para terceiros. Com isso, há o risco de, pouco a pouco, transformar a educação em um serviço público não estatal, organizado sob os moldes da engenharia do capital, a qual visa, acima de tudo, a lucratividade. Tal modelo põe em xeque o acesso universal e igualitário das pessoas a esse direito, como também pode provocar perdas irreparáveis no que diz respeito à qualidade da educação, tendendo reduzi-la ao ensino de métodos e técnicas utilitárias às demandas do capital, deixando de lado o conhecimento, a cultura como totalidade dos saberes produzidos pela humanidade e transformados em saber escolar.

Ademais desse aspecto, não se pode tratar dessa questão sem fazer um recorte de classe, em que está evidente que a classe trabalhadora é a mais prejudicada nesse processo, por não possuir as condições materiais necessárias para acessar uma educação de boa qualidade, tal qual a elite da sociedade.

O segundo elemento de análise acima indicado é parte desse processo de encolhimento do Estado perante a política de educação brasileira. Com a transferência da prestação e gestão dos serviços educacionais para instituições da sociedade civil, por meio de contratos de gestão e de termos de parceria ${ }^{3}$, o Estado transfere sua responsabilidade sobre a gestão da educação para organizações de interesse público, as quais nada mais são do que grandes grupos empresariais interessados em obter ganhos financeiros com a oferta de serviços educacionais, escondidos sob a roupagem de fundações não lucrativas.

Para além disso, a investida desses grupos incorre não somente sobre a administração escolar, mas também sobre a organização dos currículos escolares e de todo o sistema de ensino, de forma a promover o alinhamento com a perspectiva empresarial. Destarte, conforme assevera Krawczyk (2014), o setor do empresariado vem assumindo, paulatinamente, um lugar privilegiado na definição das políticas educativas, elaborando propostas que buscam aplicar modelos de gestão empresarial e enaltecer os conhecimentos alinhados com o pragmatismo. Nesse sentido, retira-se da educação o caráter de direito para configurá-la como um negócio.

\footnotetext{
${ }^{3}$ Dispositivos legais para se instituir compromisso entre o Estado e uma entidade pública estatal (agências executivas) ou uma entidade pública não estatal (organizações sociais) (Adrião, 2017).
} 
Tal como as empresas educacionais, outro grupo tende a se beneficiar com as reformas propostas para a educação no Brasil, e que está associado ao projeto de ampliação da EAD, qual seja: o grupo que envolve as grandes empresas de tecnologia da informação e comunicação. Eis aqui o terceiro aspecto que dá suporte ao projeto capitalista de privatização da educação no país.

No contexto escolar remoto o apelo exacerbado às plataformas digitais corresponde aos interesses das empresas transnacionais do mercado tecnológico digital que compõem o Big Data - Apple, Google, Facebook, Microsoft e Amazon (Fiera et al., 2020). Esse direcionamento estimulado na pandemia tende a ser tratado como uma das possibilidades de ampliação do acesso das pessoas à educação, tornando fundamental aquilo que deveria ser apenas complementar à educação presencial, isto é, o ensino a distância. Nesse aspecto, é desnecessário dizermos, evidentemente, que os maiores beneficiados com essa proposta educacional não serão os/as educandos/as, mas as empresas de tecnologia da informação e comunicação, cujos rendimentos são alavancados com todo esse movimento.

Diante disso, a pandemia parece ter trazido consigo mais uma peça que faltava na engrenagem que fará funcionar o projeto de reforma da educação brasileira. Os discursos enaltecedores da EAD e estimuladores da iniciativa privada, associados às ideias de que o modelo de educação preconizado é o mais adequado à realidade do país, emergem como estratégia de convencimento da população para tal mudança. O que podemos interpretar nas entrelinhas desses discursos, entretanto, é que tais mudanças apenas corroboram com a lógica mercantil capitalista, em que os interesses econômicos se sobrepõem às demandas sociais mais urgentes, obedecendo as metas de expansão do capital.

\section{Considerações Finais}

Diante do exposto, podemos inferir que a pandemia da Covid-19 agudizou o grave problema da educação brasileira e trouxe consigo a perspectiva de abertura total aos interesses do capital. $\mathrm{O}$ formato impresso nesse contexto tende a fortalecer as características que vêm, ao longo dos anos, sendo desenvolvidas na política de educação do país, como a precarização, a privatização, o tecnicismo e o ensino a distância, características essas conciliadas com o projeto neoliberal do Estado e com os objetivos de lucratividade do capital financeiro.

Desse modo, as perdas para a educação nacional são imensuráveis, pois essa nova configuração traz comprometimentos tanto para a democratização da educação, para que esta seja acessível de forma igualitária a todos os indivíduos, quanto para os conteúdos dos currículos escolares, cada vez mais "enxutos", permeados por uma lógica utilitarista e esvaziados de um caráter crítico e transformador. Nesse sentido, a educação deixa de ser concebida como ferramenta de construção do conhecimento e passa a ser tomada como mero instrumento de reprodução dos interesses e metas do sistema vigente.

Para além disso, a forma então preconizada reforça a desigualdade educacional no Brasil, em que a parcela mais vulnerável da população, pertencente à classe trabalhadora, é severamente prejudicada e assiste, quase inerte, a negação/retirada de mais esse direito. Este que, assim como outros direitos - saúde, moradia, assistência social, previdência, cultura, etc. - estão sendo excluídos do rol de obrigações do Estado que, pouco a pouco, firma compromisso com a proposta neoliberal.

Nesse sentido, a pandemia acarretará consequências maléficas duradouras para a saúde populacional, para a economia, para a educação e para outras políticas sociais, estabelecendo um novo contexto social. Este que não pode ser considerado de modo algum como o "novo normal", até mesmo porque não podemos dizer que, antes da pandemia, vivíamos um estado de normalidade. A expressão "novo normal" sugere uma reação de conformismo, de resignação diante de uma realidade de degradação da vida, de próprio desprezo pelas condições dignas de sobrevivência das pessoas. Assim, o que 
podemos dizer da crise humanitária instalada é que ela provoca, sobretudo, a "piora" do que já podia ser considerado uma anormalidade.

É válido ressaltar que as consequências da pandemia irão repercutir na sociedade por longa data, gestando novas dinâmicas nas relações sociais, econômicas e políticas como um todo. No âmbito da política de educação brasileira, os seus efeitos podem ser ainda mais devastadores do que aqueles apontados neste estudo. Desse modo, tornam-se necessárias futuras pesquisas para avaliar a dimensão dos prejuízos causados pela crise sanitária, sob o ponto de vista da exclusão educacional.

\section{Referências}

Adrião, T. (2017). A privatização da educação básica no Brasil: Considerações sobre a incidência de corporações na gestão da educação pública. In Araújo, L. \& Pinto, J. M. R, (Orgs). Público X privado em tempos de crise (pp. 16-37). Fundação Lauro Campos e Fineduca.

Andrade, G. P. S. B., Barbosa, L. A., Cardoso, M. S., \& Oliveira, R. M. S. R. (2021). Desafios para a construção de práticas docentes em tempo de pandemia. Research, Society and Development, 10(1). https://doi.org/10.33448/rsd-v10i1.11834

Antunes, R. (2020a). Coronavírus: O trabalho sob fogo cruzado. Boitempo.

Antunes, R. (2020b). O privilégio da servidão: O novo proletariado de serviços na era digital. Boitempo.

Demo, P. (2000). Metodologia do conhecimento científico. Atlas.

Fiera, L., Evangelista, O., \& Flores, R. (2020). Chantagem como estratégia para assegurar o "direito de aprendizagem" aos "vulneráveis. In Soares et al. Coronavírus, educação e luta de classes no Brasil (pp. 21-28). Brasil: Editora Terra sem Amos.

Frigotto, G. (1999). O enfoque da dialética materialista histórica na pesquisa educacional. In Fazenda, I. C. A. (Org.). Metodologia da pesquisa educacional (pp. 69-90). (5a ed.), Cortez.

Gil, A. C. (2002). Como elaborar projetos de pesquisa. Atlas.

Gonçalves, D. N., Lima, I. P. F., \& Freitas, R. M. F. (2020). Educação superior em tempos de pandemia: uso de tecnologias e condições de trabalho de docentes. In Frota, F. H. S., Frota, M. H. P., \& Silva, M. A. L. O impacto do COVID-19 nas políticas públicas [livro eletrônico], Edmeta Editora.

Harvey, D. (2020). Política anticapitalista em tempos de coronavírus [Blog]. https://blogdaboitempo.com.br/2020/03/24/david-harvey-politica-anticapitalistaem-tempos-de-coronavirus/

Krawczyk, N. (2014). Ensino médio: Empresários dão as cartas na escola pública. Educação \& Sociedade. 35(126), 21-41. https://www.scielo.br/pdf/es/v35n126/02.pdf.doi:0.1590/S0101-73302014000100002

Lüdke, M., André, M. E. D. A. (2012). Pesquisa em educação: Abordagens qualitativas. E. P. U.

Marinho, C. H., Freitas, I. C. M. (2020). Experiências com o ensino remoto: relatos de professores da educação básica no Ceará. In Frota, F. H. S., Frota, M. H. P., \& Silva, M. A. L. O impacto do COVID-19 nas políticas públicas. Fortaleza: Edmeta Editora.

Marx, K. (2011). Grundrisse: Manuscritos econômicos de 1857- 1858. Esboços da crítica da economia política. Boitempo.

Minayo, M. C. S. (1994). Pesquisa social: Teoria, método e criatividade. Vozes, 1994.

Senhoras, E. M. (2020). Coronavírus e educação: análise dos impactos assimétricos. Boletim de Conjuntura, 2(5), 128-136. https://revista.ufrr.br/boca/article/view/Covid-19Educacao. 10.5281/zenodo.3828085

Soares, S. B. V. (2020). Coronavírus e a modernização conservadora da educação. In Soares, S. B. V. et al. Coronavírus, educação e luta de classes no Brasil (pp. 5-14). Editora Terra sem Amos. 